\title{
Consciousness and Emotion
}

Demian Whiting

\begin{abstract}
It is widely held that emotions are conscious mental states. But what exactly is meant by saying that emotions are conscious? Also why does it matter whether emotions are conscious? Does the fact of emotions being conscious have metaphysical or epistemological implications, for instance? And is it the case that emotions are always conscious? Are there any counterexamples to that idea? The purpose of this chapter is to explore these questions and to outline possible ways of answering them.
\end{abstract}

If we fancy some strong emotion, and then try to abstract from our consciousness of it all the feelings of its characteristic bodily symptoms, we find that we have nothing left behind, no 'mind-stuff' out of which the emotion can be constituted...

(William James 1884: 193)

It is surely of the essence of an emotion that we should feel it, i.e. that it should enter consciousness.

(Sigmund Freud 1950: 109-110)

What is the relationship between emotion and consciousness? Is consciousness needed for emotion? Might it even be the case that emotion is required for consciousness? This latter idea is an interesting one. So, we might wonder what it would be like to be a creature that has no emotion at all, no pleasure occasioned by things when they go right, no sorrow when things go wrong, no fear occasioned by threats to oneself or others. Certainly, it would be nothing like what it is like to be a normal human being. Perhaps there are people who experience very little emotion, but, if so, such cases are extremely rare. Even psychopaths have some emotion despite lacking the deeper emotional responses that characterize a fully functioning and flourishing human life. Nevertheless, it is not obvious that a creature that lacked emotion could have no conscious experience. Surely, there are other forms of consciousness that such a creature could undergo if not emotional consciousness. What about perceptual consciousness, or the consciousness that comes with thinking a thought or working out a puzzle? Possibly, what it is like to think a thought or to visually perceive something would be very different without accompanying emotional consciousness. So, perhaps, such mental activity would lack a certain vibrancy or color, so to speak, if there were no accompanying emotion. But, it is unclear what the justification would be for saying that there cannot be consciousness without emotion.

Much more plausible, we might think, is the idea that consciousness is needed for emotion. Indeed, it might seem obvious that emotions are conscious and necessarily or constitutively so. After 
all, we speak about emotions as feelings and feelings are felt, are they not? This claim that emotions are conscious is the idea to be explored in this chapter, then. More specifically, I address three sorts of questions. First, what is meant by saying that emotions are conscious? Second, why does it matter whether emotions are conscious? For instance, does saying that emotions are conscious have metaphysical or epistemological implications? And third, is it the case that emotions are always conscious? What about longstanding or persistent emotions, such as an enduring fear of heights or love for another person? Also, can there be episodic or occurrent emotional states that are not conscious?

\section{What is meant by saying that emotions are conscious?}

In this chapter 'consciousness' will be understood as referring to phenomenal consciousness or, in other words, the what-it-is-likeness of being in or occupying a certain mental state (Nagel 1974). It follows that to say that emotions are conscious is to say at a minimum that there is something that it is like for us to undergo emotion, or that emotions have a characteristic feel or phenomenology. For instance, it might be held that fear has an edgy feel, and anger has an irritable or hot-headed feel. That being said, note that the claim that emotion feels a certain way doesn't on its own tell us anything about the character of emotional phenomenology. To be sure, that claim is consistent with holding that emotional phenomenology takes the form of bodily sensation or feeling. For instance, about fear and anger, William James writes:

What kind of an emotion of fear would be left, if the feelings neither of quickened heart-beats nor of shallow breathing, neither of trembling lips nor of weakened limbs, neither of goose-flesh nor of visceral stirrings, were present, it is quite impossible to think. Can one fancy the state of rage and picture no ebullition of it in the chest, no flushing of the face, no dilatation of the nostrils, no clenching of the teeth, no impulse to vigorous action, but in their stead limp muscles, calm breathing, and a placid face? The present writer, for one, certainly cannot.

(James 1884: 194)

According to James, then, what it is like to undergo an emotion is what it is like to undergo or experience certain bodily changes. James may or may not be right, but the claim that emotions feel a certain way need not rule out other views, however. So, perhaps, emotional phenomenology has a cognitive or perceptual-like character. For instance, perhaps what it is like to feel afraid is what it is like to judge or perceive something as fearsome or dangerous (e.g. Solomon 1993; Döring 2007; Poellner 2016). Or, perhaps, emotional phenomenology has a desire-like character. For instance, perhaps what it is like to feel afraid is what it is like to want to run away or to avoid the object feared (e.g. Maiese 2011). Or, perhaps, emotional phenomenology is composite in nature, comprising cognitive, sensory, and conative elements (e.g. Kriegel 2012). Or then again, perhaps emotional phenomenology is not described 
properly by any of the views just outlined; for perhaps emotional phenomenology is altogether distinctive and sui generis, unlike any other kind of consciousness.

The claim that emotions feel a certain way is consistent also with two further ideas. To begin with, it is consistent with the view that the what-it-is-likeness of emotion is a non-constitutive or extrinsic property of emotion. On this view, although emotions feel a certain way, emotions are not constituted by how they feel, in the same way that cuts and bruises, for instance, are generally taken not to be constituted by the way they feel to us. So, perhaps emotions are states of bodily arousal that feel a certain way when undergone, but - as with such things as cuts and bruises - are to be characterized entirely independent of how they feel. Call this the 'non-constitution view'. But, the claim that emotions feel a certain way is consistent as well with a stronger and potentially more interesting view, namely the idea that emotions are constituted by their characteristic phenomenology or way of feeling. Call this the 'constitution view'. According to this stronger view there is no distinction to be had between the emotion and the way the emotion feels to us.

Is there a way of deciding between the constitution and non-constitution view? Considerations relevant to answering that question might be conceptual and/or empirical. Conceptual considerations draw on what our idea of emotion might tell us about emotion. That we talk about emotions as feelings might provide some support for the constitution view, since arguably it is part of our concept of feeling that feelings are felt and necessarily so. Another conceptual consideration in favor of the constitution view might be that although we say emotions are conscious, we don't similarly say that cuts and bruises are conscious, even though cuts and bruises feel a certain way when we experience them. For instance, cuts and bruises can be painful, and they also look a certain way when viewed in normal lighting conditions. Why don't we say that cuts and bruises are conscious? One reason might be that saying something is conscious is saying more than merely that thing feels a certain way, namely it is saying that thing comprises the way it feels, or has consciousness built into it, so to speak.

Empirical considerations, on the other hand, resort to observational data, our introspective observations of the emotions that we undergo, for instance. Here is how one simple argument for the constitution view grounded in the experience might go, then. Next time you undergo an emotion - say, an episode of fear or anxiety - introspectively attend to the emotion and hold what you are attending to in mind. Then introspectively attend to how the emotion feels and hold what you are attending to in mind. Finally, having done both of these things, let it be asked: when moving from the emotion to how the emotion felt did you experience a shift in attention? Did you find yourself attending to one thing when attending to the emotion and another thing when attending to how the emotion felt? Plausibly, it might be held that you experienced no change in attention at all, that what you found yourself attending to when attending to the emotion was exactly what you found yourself attending to when attending to the characteristic feel of the emotion. And if that is the case, then it seems to constitute quite a strong argument - again, one rooted in first-person observation or experience of emotion, note - for the view that emotions are indistinguishable from their characteristic ways of feeling. 


\section{Why it matters whether emotions are conscious}

If the what-it-is-likeness of emotion were a non-constitutive property of emotion, then the fact of emotion having a characteristic feel would tell us little about emotion and the kinds of things that emotions might and might not be. Of course, if emotions are constituted by something other than how they feel, then the fact of emotion feeling a certain way might still hold interest for other reasons. For instance, the existence of the phenomenology would provide us evidence for the existence of the emotion and the emotion type to which it belongs. And this might prove useful when trying to navigate the world, for example. For instance, knowing something about the emotions we are undergoing - that we are anxious or happy or angry, say - might tell us something about how we are faring, and how our behaviors might need to be modified for us to get on better. Also, if we know on the basis of their characteristic feel that we are undergoing certain emotions, then we will be in a position to share that knowledge with other people, and this might serve various personal and social goals.

However, if emotions are constituted by their characteristic feel or phenomenology, then such a fact about emotion will tell us important truths about emotion and the sorts of things that emotions might and might not be. For instance, such a fact about emotion would mean that emotions are conscious through and through, and that for an emotion to be is for an emotion to be felt or experienced by us.

Moreover, if emotions are how they feel, then that will create serious difficulties for the view that emotions are neural or bodily states, which do not seem to have consciousness built into them. Sometimes the point is made that it is conceivable that bodily or neural activity take place, but without consciousness being present, as in a zombie world, for instance (see Chalmers 1996). But whatever we think of 'conceivability arguments' (and it is sometimes held that what is conceivable is not always a good test of what is actual or possible), a simple but effective argument can be given for the view that neural or bodily states do not consist of how they might feel to us when we experience them.

In a nutshell, the argument is that if neural or bodily states comprise how they feel, then their natures would be evident to us. This is because the way something feels - for instance, the edgy feel of fear - is evident to us. Indeed, there is no part of an edgy feel (say) that is not apparent to us; fear's edginess is evident to us in its entirety, in other words. But, as with other physical phenomena, neural or bodily states have natures - namely, atomic natures - that are not evident to us, even in part. Although we can theorize about the atomic make-up of a given neural or bodily state we cannot know the atomic constitution in question by directly observing it. Therefore, bodily or neural states are by their nature distinct from the way they feel, and it follows that emotions cannot be bodily or neural states if emotions are not distinct from the way they feel. And, note, that it would be no good to reply that bodily or neural states might be the way they feel because the way they feel might have a nature that is not evident to us. If something is a property that it has and which is apparent to us - for instance, if a bodily or neural 
state is the way it feels to us - then the nature of the property with which the thing is identical will be evident to us as well. This is because the thing and its property are one and the same, and, therefore, their natures, the properties composing them, will be the same also.

To say that emotions are not bodily states isn't to rule out the idea that emotions require a body, however. Indeed, there is ample empirical evidence to show that bodily activity or change underlies and shapes the emotions that we feel (cp. Damasio 1999; Prinz 2004; Maiese 2011). For instance, it has been shown that fear, anger, joy, sadness, surprise, and disgust (the so-called six basic emotions) can be distinguished by patterns of autonomic activity (Levenson et al. 1990; Levenson 2002). And, again, other studies have identified areas of the brain that are implicated in emotion. For instance, the amygdala has been linked with fear (LeDoux 2000), and amygdala hyperactivation has been found to be associated with anxiety disorders (Garfinkel and Liberzon 2009). Moreover, it has seemed to many emotion theorists from William James onwards, that emotions just are feelings or sensations of bodily movement or activity - that fear, for instance, is the feeling or sensation of quickened heartbeats, weakening limbs, and trembling lips - or, at least, that emotions are experienced by us as occupying parts of the body (e.g. James 1884; Prinz 2004; Whiting 2011; Maiese 2011). Such considerations lend support to the idea that emotions require a body. If emotions are constituted by their characteristic phenomenology, then there may not be a relationship of identity between emotion and bodily activity, but there is reason to think there is a very close relationship all the same.

If emotions are constituted by the way they feel, then this would have important implications for the epistemology as well. In particular, that fact about emotion would entail that attention to the phenomenology of emotion will be inescapable if we wish to wish to know something about emotion's intrinsic properties or character. In that case, attending to other observable data, such as brain scans and observable bodily changes, would be of limited value insofar as getting to know the nature of emotion is concerned - though, again, such forms of empirical inquiry might tell us about the physical structures that underlie emotion, and out of which emotion may emerge somehow.

Also of limited value would be the language that we employ about emotion. Indeed, if the way to get to know about emotion is by attending to what it is like to undergo emotion, then we will have reason to accept everyday talk about emotion only if such talk is vindicated by the experience of emotion. As way of illustration, notice that we commonly talk about emotions being about or of things. For instance, I might say that I am frightened of a dog or frustrated about the weather. Everyday talk suggests that emotions are intentional or object-directed mental states, in the same way that thoughts, desires and perceptual states are commonly taken to be intentional mental states. But is such talk actually borne-out by the phenomenology of emotion? Although some emotion theorists answer in the affirmative (e.g. Tye 2008; Montague 2009; Maiese 2011; Kriegel 2012; Lutz 2015), there is reason to be sceptical. This is because it might be argued that what we find when we attend to the phenomenology of emotion are 'raw' feels with no representational or intentional character of their own (see Whiting 2011). For instance, consider what it is like to undergo a fear sensation in the stomach region. To be 
sure, when we undergo fear thoughts about the object exciting the fear are never far away and those thoughts have an object-directed character or feel. But the fear itself? Plausibly, it might be held that attention to the phenomenology shows us that such a state is 'blind', thus promising to vindicate Hume's claim that emotions are 'original existences' with no representational quality of their own (Hume 1969). In this respect, it might be thought that emotions more closely resemble pain sensations, for instance, which also seem to fail to phenomenally manifest an object-directed character.

If emotions comprise their phenomenology, then the only reply available to someone who thinks that emotions are intentional, but accepts that emotions don't manifest an object-directed character, would be to claim that the intentional properties of emotion are extrinsic or non-constitutive properties of emotion. This might be the view of someone who thinks that intentional relations are types of causal relations, for instance. On such a view, a state of fear (say) might be nothing other than a bodily sensation (say), but have intentional content in virtue of standing in some causal relation with what it represents or is about. On such a view, the representational properties of an emotion are not of the nature of emotion, the emotion itself being nothing more than a bodily feeling or sensation.

Now, of course, even supposing that the intentional properties of a mental state are extrinsic in this sense, this would provide us with reason only to question whether emotion lacks such properties. It would not be reason to reject the idea that attending to the phenomenology is crucial for getting to know the nature of emotion or emotions of different types, which pertains to those properties that are intrinsic to emotion. But, moreover, there is good reason to think that intentional properties are felt properties in fact, and, therefore, would be evident to us in the experience of emotion if emotions are truly intentional. Indeed, introspection makes compelling the idea that the intentional properties of a bona-fide representational mental state are phenomenally manifest in the mental state. For example, the representing of Paris as being the capital of France is a property that is manifest in the thought that Paris is the capital of France, and the presentation of a red object in front of me is very much part of the phenomenology of a visual experience of a red object in front of me (see Chalmers 2004; Horgan and Tienson 2002; Kriegel 2012; Whiting 2012; Whiting 2016). And, if it is the case that intentional properties are phenomenally manifest properties, then emotions will lack intentional properties if emotions do not phenomenally manifest such properties.

But, is it really the case that emotions fail to phenomenally manifest intentional properties? Here, various reasons might be given for answering in the negative. To begin with, one might appeal to a form of 'strong representationalism', according to which the phenomenal character of a mental state is identical to the representational content of the mental state (e.g. Tye 2000, 2008). The worry with this way of arguing, however, is that it risks begging the question. If emotions do not manifest intentional properties, then surely the right thing to say is that emotion's phenomenal character cannot be identical to emotion's representational content, as emotion would then seem to lack any such content.

A more promising view, perhaps - and one that might be congenial to some strong representationalists as well - would be to hold that even if emotions are not experienced as being 
directed at things outside the body, nevertheless emotions are experienced as being about the body or its parts. That might be the view of someone who thinks that emotions are sensations or perceptions of bodily change or activity (see, for instance, James 1888; Prinz, 2004; Tye, 2000, 2008). And arguably, this is the most promising line for someone to adopt, given the close relationship that clearly exists between emotion and the body. That being said, however, an opposing view would be to maintain that although we do indeed experience emotions as taking place or being instantiated in the body, that isn't the same as saying that emotions are experiences of the body.

A final reason to doubt that emotions fail to manifest an intentional character is more concessionary, insofar as it aims to show only that some emotions manifest such a character. For what about so-called 'higher-cognitive' emotions such as pride and guilt, which might obviously seem to involve intentional properties? Thus, isn't pride bound up with ideas of the self and guilt bound up with ideas of personal wrongdoing? Arguably, pride and guilt are bound up with such ideas, but what are we to infer from this? To begin with, we might accept that pride and guilt manifest an intentional character, but disagree this shows that emotions have such a character. For, perhaps, it shows only that pride and guilt are compound states, comprising non-intentional emotions and mental representations. Alternatively, we could accept that states such as pride and guilt are emotions and nothing more, but deny that attention to the phenomenology shows they have the intentional properties they might be claimed to have. For, perhaps, guilt manifests as a distinctive anxiety-like sensation (say) but qualifies as 'guilt' in virtue of being triggered by thoughts of personal wrongdoing, and, perhaps, pride manifests as a pleasurable feeling (say) but qualifies as 'pride' in virtue of being triggered by thoughts of the self. This would be to allow that pride and guilt are bound up with certain thoughts (for without the triggering thoughts the feelings would not qualify as pride and guilt), while denying that pride and guilt comprise those thoughts, the emotions themselves being objectless feeling states.

\section{Unconscious emotions}

Barring some notable exceptions (e.g. Damasio 1999; Prinz 2005a; Winkielman et al. 2005), the idea that emotions are always conscious or felt is a view that has been held by a great many psychologists and philosophers of emotion (e.g. James 1884; Clore 1994; Panksepp 2005; Hatzimoysis 2007; Maiese 2011; Whiting 2011; Deonna and Teroni 2012). Even Freud - who is often credited with showing us the unconscious - can be attributed the view that emotions are felt necessarily and that there are no such things as unconscious emotions (e.g. Freud 1950). But is the view that emotions are always conscious a correct one? There are two sorts of cases that might be offered as counterexamples to that view. First, there are those cases involving emotions sometimes considered to have dispositional natures, such as a fear of heights. Second, there are those cases involving emotions that have occurrent or episodic natures, but which are held by some emotion theorists to be unconscious. Let us consider each in turn. 
Suppose Sebastian has a fear of heights, Joan has loved her partner for many years, and Robert has been angry all day for not getting an expected pay rise. Now, it seems that we can assign these emotions to Sebastian, Joan, and Robert, even when they are not undergoing occurrent fear, or anger, or amorous affect. Thus, we can attribute a fear of heights to Sebastian and love of one's partner to Joan, even when Sebastian and Joan are dreamlessly sleeping, for instance. And, throughout the day we can attribute to Robert an anger for not getting an expected pay rise, including at times in the day when Robert is not feeling angry (for instance, when he is working or otherwise preoccupied and not thinking about the pay rise that never materialized).

For this reason, some philosophers have taken these emotional states to have dispositional or non-episodic natures (see, for instance, Lyons 1985; Prinz 2003; Prinz 2004; Goldie 2010). For instance, Sebastian's fear of heights might be considered to be a disposition to undergo occurrent states of fear in the perceived presence of heights, Joan's love for her partner might be taken to be a disposition to undergo occurrent positive or amorous emotions when perceiving or thinking about her partner, and Robert's anger for not getting an expected pay rise might be taken to comprise a tendency throughout the day to get worked up when thinking about the pay rise that failed to materialize (see e.g. Prinz 2003; Naar 2013). Unlike occurrent mental states, which tend to be short-lived and possess a characteristic phenomenology, emotional states such as a fear of heights, love for one's partner, and anger for not getting a pay rise, might seem to be longstanding or persistent mental states that need have no phenomenology of their own. There is nothing that it is like to be afraid of heights or to love one's partner when dreamlessly sleeping, for example. But that might look to be tantamount to saying that these dispositional or longstanding states are emotions that are not conscious.

However, the idea that emotions can be both episodic mental states and the dispositions to undergo such episodic mental states commits us to an unhappy metaphysics. Indeed, it would be to hold that a given emotion-type - fear or love or anger, for instance - can have two natures or be more than one thing, metaphysically-speaking, and that looks to be the sort of view we should try to avoid adopting if possible. Therefore, unless we wish to reject the idea that there are episodic or occurrent emotions, we need a way of treating longstanding emotions that acknowledges there are episodic emotions only. And here there are two strategies available to us.

The first is to insist that mental states such as a fear of heights are emotional dispositions, not dispositional emotions. Thus, although to fear heights is to be disposed to undergo episodic emotions in the perceived presence of heights that amounts to saying that a fear of heights is the disposition to undergo emotion, and not an emotion itself (see e.g. Deonna and Teroni 2012). This strategy accepts that mental states, such as a fear of heights or love of one's partner, have dispositional natures, but denies this entails some emotions are dispositional, since the mental states in question are not emotions.

An alternative strategy, however, is to say that such mental states are emotions because it turns out they are episodic emotions and not the dispositions to undergo those emotions as originally supposed (see Whiting, unpublished). This strategy requires us to distinguish between the emotion and 
the having of the emotion, and holds that it is the having of the emotion that has a dispositional nature, not the emotion itself. And here like examples are not difficult to find. For instance, many birds have alarm calls that they emit in situations of danger. Moreover, it is true to say of birds that they have alarm calls when they are sleeping and not emitting those calls. Are we to conclude that the alarm calls of birds are the dispositions to emit certain calls or sounds? The answer is negative. Although to have an alarm call might be a disposition to emit certain calls when encountering danger, the calls themselves have episodic, not dispositional natures.

And likewise, the argument goes, we can agree that what it is to be in love with one's partner, or to be afraid of heights, or to be angry all day for not getting a pay rise, is to be such so as to undergo certain episodic emotions when particular circumstances obtain. So, for instance, if throughout the day Robert doesn't get worked up when reflecting on his failure to get an expected pay rise, then it would seem wrong to describe Robert as being angry that day for failing to get an expected pay rise. However, that is not to say that the emotions themselves have dispositional natures. Indeed, according to the present way of treating these emotional states, the emotions themselves are to be viewed as discrete mental episodes, albeit discrete mental episodes that are undergone when certain circumstances obtain. For instance, Robert's anger for not getting an expected pay rise is to be identified with the angry feelings that Robert undergoes throughout the day when reflecting on his failure to get a pay rise.

Now, regardless of whether we opt for the first strategy or the second strategy just outlined, the important thing to note is that both strategies would entail that mental states, such as a fear of heights or love of one's partner, fail to be counterexamples to the idea that emotions are always conscious. If we adopt the first strategy, then these mental states turn out to be other than emotions. On the other hand, if we adopt the second strategy, then although these mental states turn out to be emotions they are emotions only because they are episodic, not dispositional, mental states, and we will still lack positive reason for thinking the emotions in question can be anything other than conscious.

The second group of cases that might be offered as counterexamples to the idea that emotions are always conscious might seem to pose a greater threat to that idea, because they pertain to emotional states that almost everyone will from the beginning agree have episodic, not dispositional, natures. Thus, a number of writers have drawn on findings in empirical psychology and elsewhere in support of the view there are unconscious emotions of an episodic kind (see e.g. Kihlstrom et al. 2000; Winkileman et al. 2005; Prinz 2005a; Prinz 2005b; Lane 2007; Smith and Lane 2016). However, as we shall see, it is far from clear the evidence in question does show this.

To begin with, then, some of the findings support only the view that the causes of emotion are not always consciously felt. Consider a study by Robert Zajonc, which found that repeated exposure to subliminal stimuli influenced people's preferences (Zajonc 1980; see also Öhman and Soares 1994). Now, although the findings support the idea that the elicitors of emotion can lie outside conscious awareness, they don't show that emotion itself can be unconscious. 
And in other cases, the evidence shows only that people can mislabel or misidentify emotion (see also Deonna and Teroni 2012: 16-17). For instance, Smith and Lane describe the case of a bereaved husband who originally thinks he is angry with what he perceives to be the unfairness of life, but comes to realize he is angry with his spouse for dying (Smith and Lane 2016). But, even supposing that this is a case of misidentified emotion, and not merely a failure to recognize the real cause of an emotion, such a case as this also fails to show that emotions can be unconscious. This is because an emotion that is mislabelled or misidentified is not the same as an emotion that fails to have a characteristic phenomenology.

More puzzling, perhaps, are those cases where there is reason to think emotions have been undergone but which involve people who fail to consciously report on their emotions (Winkielman et al. 2005; Winkielman et al. 2007). Such cases concern the emotions themselves, and not the causes of the emotion, and involve not misidentification, but wholesale unawareness of emotion. Consider a much-discussed experiment in which participants were subliminally shown happy, angry or neutral faces depending on the group to which they had been assigned (Winkielman et al. 2005). Participants were then asked to rate the pleasantness of a fruit beverage. It was found that participants who had been shown happy faces rated the pleasantness of the beverage higher than those shown angry or neutral faces. It was also found that participants shown happy faces consumed larger amounts of the beverage than those shown angry or neutral faces. Strikingly, however, participants reported no differences in how they felt. For this reason, the study has been taken to show that emotions can be unconscious. The behaviors of participants evidence there being emotions explaining differences in behaviors, but these emotions were not detected by participants (Winkielman et al. 2005; Prinz 2005b; Smith and Lane 2016).

Now, it can be questioned whether the Winkielman et al. study succeeds in showing that participants failed to report accurately on their emotions. As just explained, the justification for thinking that participants underwent changes in emotion is that this is the most plausible explanation for differences in behaviors observed. Winkielman et al. consider one alternative explanation, namely that participants might have cognitively appraised their situations differently when presented with subliminal stimuli, and these cognitive appraisals explained differences in behavior (Winkielman et al. 2005: 133). However, it is unclear whether this is the only possible alternative explanation available. For instance, perhaps the subliminal stimuli were themselves directly responsible for differences in behavior, as might be the case if certain subliminal stimuli have the power to influence or modulate how people are disposed to behave. This would make the receiving of subliminal stimuli, and not an emotion or cognitive appraisal, responsible for the differences in behaviors, and would be consistent with supposing that participants reported on their emotions accurately.

But suppose the explanation that Winkielman et al. give for study participants' behaviors is correct. Does the fact that participants failed to be able to report on their emotions establish the truth of the emotion without consciousness view? It is difficult to see how, since there is nothing to the claim 
that emotions have a characteristic feel that rules out the idea that people can sometimes fail to register or reflect on their emotions (cp. Lambie and Marcel 2002, Maiese 2011, Deonna and Teroni 2012). After all, few would deny there is something that it is like for young children to undergo emotion, but it would surely be stretching things to say that young children are able to reflect on and form beliefs about their emotions.

Another way to make the point is by distinguishing between two ways in which talk of conscious awareness of emotion might be taken. On the one hand, when we say someone is consciously aware of an emotion we might mean the person is experiencing an emotion. Here conscious awareness is the sort of awareness in virtue of which there is something that it is like to undergo an emotion, or in virtue of which an emotion has a phenomenology. After all, an emotion can have a characteristic phenomenology only insofar as the emotion is experienced or felt by us. But this sense of 'conscious awareness' is to be distinguished from another use of that term, where conscious awareness is a matter of consciously reflecting on, or forming certain beliefs about, an emotion, for instance the belief that one occupies the emotion in question. Here conscious awareness is knowledge of undergoing a certain emotion, a state of fear, for instance.

And therein lies the problem. Pace Winkielman et al. why not think that the study results show only that there can be changes in emotion that people can fail to consciously reflect on or form certain beliefs about? Indeed, there are a number of reasons why study participants might have been unable to reflect on changes in felt emotion. For instance, the changes might have been too subtle and/or shortlived to be registered or reflected on (which is consistent with supposing that such changes might nevertheless have had significant effects on behavior, note). And although the authors of the study acknowledge this kind of response to their argument (Winkielman et al. 2005:132), they say little to remove or mitigate the worry.

There is reason to think the evidence just discussed does not establish the existence of unconscious emotions. Although the evidence might succeed in showing that people can fail to consciously register or reflect on their emotions, there is reason to doubt that the evidence shows there can be emotions that are unfelt or which fail to have a characteristic feel. Still, does the possibility remain that considerations may yet be presented demonstrating that emotions can be unconscious? It is unclear how we can rule out that possibility altogether, I suppose. Nevertheless, one reason for thinking that emotions are always conscious has been alluded to already in this paper. For suppose we are able to see from our own case that an emotion of a certain type is constituted by its characteristic feel. For instance, suppose we can see by means of introspection that an episode of fear is indistinguishable from its unpleasant edgy feel. But, if that is the case, and an emotion of a certain type is indistinguishable from its characteristic feel, then how can an emotion of that type fail to be conscious, or fail to feel a certain way? To think the emotion in question can be unconscious would be to think that an emotion of that type does and doesn't comprise its phenomenology, which isn't a very cogent position to hold. In 
other words, then, if emotions are constituted by their characteristic feel, then emotions cannot be unconscious, and the task of seeking to show otherwise will indeed be forever a hopeless one.

Should we conclude that emotions are always conscious, then? Again, only if emotions are constituted by their characteristic feel. Earlier in the chapter conceptual and empirical considerations were given in support of what I called the 'constitution view'. I will leave it to the reader to judge whether they succeed or not. Certainly, they are likely to need developing. But needless to say, if those considerations fail, then this will be either because the constitution view is not supported by our concept of emotion, or because the constitution view is not supported by our observations of emotion. Thus, if it turns out that our concept of emotion does not support the idea that emotions are constituted by how they feel - either because our concept of emotion supports an alternative view, or because conceptual considerations are unable to establish deep metaphysical truths (thus, perhaps such considerations only ever tell us about our idea of emotion) - then the constitution view cannot be endorsed on conceptual grounds. Similarly, if it turns out that introspection fails to support the idea that emotions are constituted by how they feel - either because it supports an alternative view, or because introspection is unable to establish deep metaphysical truths (see, for instance, Schwitzgebel 2008; Schwitzgebel 2011) - then we will lack reason rooted in first-person experience for accepting the constitution view.

For my part, I have defended elsewhere the claim that introspection can deliver us truths about the nature of conscious mental states, including our emotions (Whiting 2016). And as regards the question of whether introspection might support instead the view that emotions don't comprise their phenomenology, again my thinking is that although it is clear that when we observe cuts and bruises (say) we see there to be a gap between the things observed and how they feel to us, we find no such gap in the case of emotions and how they feel to us. And it is for this reason that my money is on there being no such thing as an unconscious emotion. ${ }^{1}$

\section{Note}

1. I am very grateful to Paul Gilbert and Rocco Gennaro for helpful comments on an earlier draft.

\section{References}

Chalmers, D. (1996) The Conscious Mind: In Search of a Fundamental Theory, New York and Oxford: Oxford University Press.

---- (2004) “The Representational Character of Experience," in B. Leiter (ed.) The Future for Philosophy. Oxford: Oxford University Press.

Clore, G. (1994) "Why Emotions Are Never Unconscious," in P. Ekman and R. Davidson (eds.) The Nature of Emotion: Fundamental Questions. New York: Oxford University Press. 
Damasio, A. (1999) The Feeling of What Happens: Body and Emotion in the Making of Consciousness. New York: Harcourt Brace.

Deonna, J. and Teroni, F. (2012) The Emotions. A Philosophical Introduction. Oxon: Routledge.

Döring, S. (2007) "Seeing What to Do: Affective Perception and Rational Motivation," Dialectica 61: 363-394.

Freud, S. (1950) Collected Papers (J, Riviere, Trans. Vol. 4) London: Hogarth Press and The Institute of Psychoanalysis.

Garfinkel, S. and Liberzon, I. (2009) "Neurobiology of PTSD: A Review of Neuroimaging Finding," Psychiatric Annals 39:370-381.

Goldie, P. (2010) "Love for a Reason," Emotion Review 2: 61-67.

Hatzimoysis, A. (2007) “The Case Against Unconscious Emotions,” Analysis 67: 292-299.

Horgan, T. and Tienson, J. (2002) "The Intentionality of Phenomenology and the Phenomenology of Intentionality," in D. Chalmers (ed.) Philosophy of Mind: Classical and Contemporary Readings. Oxford: Oxford University Press.

Hume, D. (1969) A Treatise of Human Nature. London: Penguin.

James, W. (1884) "What is an Emotion?" Mind 9: 188-205.

Kihlstrom, J., Mulvaney, and B., Tobias, T. (2000) "The Emotional Unconscious," in E. Eich, J. Kihlstrom, G. Bower, J. Forgas, and P. Niedenthal (eds.) Cognition and Emotion, New York: Oxford University Press.

Kriegel, U. (2012) “Towards a New Feeling Theory of Emotion," European Journal of Philosophy 3: 420-442.

Lambie, J. and Marcel, A. (2002) "Consciousness and the Varieties of Emotion Experience: A Theoretical Framework," Psychological Review 109: 219-259.

Lane, R. (2007) "Neural Substrates of Implicit and Explicit Emotional Processes: A Unifying Framework for Psychosomatic Medicine. Psychosomatic Medicine 70: 214-231.

LeDoux. J (2000) "Emotion Circuits in the Brain," Annual Review of Neuroscience 23: 155-8

Levenson, R., Ekman, P., Heider, K., and Friesen, W. (1992) "Emotion and Autonomic Nervous System Activity in the Minangkabau of West Sumatra," Journal of Personality and Social Psychology 62: 97288.

Levenson, R. (2003) "Blood, Sweat, and Fears: The Autonomic Architecture of Emotion," Annals of the New York Academy of Sciences 1000: 348-366.

Lutz, A. (2015) "The Phenomenal Character of Emotional Experience: A Look at Perception Theory," Dialectica 69: 313-334.

Lyons, W. (1985) Emotion. Cambridge: Cambridge University Press.

Maiese, M. (2011) Embodiment, Emotion, and Cognition. Palgrave MacMillan: London.

Montague, M. (2009) “The Logic, Intentionality, and Phenomenology of Emotion," Philosophical Studies. 145: 171-192. 
Naar, H. (2013) “A Dispositional Theory of Love,” Pacific Philosophical Quarterly 94: 342-357.

Nagel, T. (1974) “What is it Like to be a Bat?" Philosophical Review 83: 435-450.

Öhman, A. and Soares, J. (1994) “'Unconscious Anxiety': Phobic Responses to Masked Stimuli," Journal of Abnormal Psychology 103: 231-240.

Panksepp, J. (2005) "Affective Consciousness: Core Emotional Feelings in Animals and Humans," Consciousness and Cognition 14: 30-80.

Poellner, P. (2016) "Phenomenology and the Perceptual Model of Emotion," Proceedings of the Aristotelian Society 116: 261-288.

Prinz, J. (2003) "Emotions, Psychosemantics, and Embodied Appraisals," in A. Hatzimoysis (ed.) Philosophy and the Emotions. Cambridge: Cambridge University Press.

----- (2004) Gut Reactions. A Perceptual Theory of Emotion. Oxford: Oxford University Press.

---- (2005a) “Are Emotions Feelings?” Journal of Consciousness Studies 12: 9-25.

---- (2005b) "Emotions, Embodiment, and Awareness," in L. Barrett, P. Niedenthal, and P. Winkielman. (eds.) Emotion and Consciousness. London: Guildford Press.

Solomon, R. (1993) The Passions: Emotions and the Meaning of Life. Indianapolis: Hackett Publishing Company.

Schwitzgebel, E. (2008) “The Unreliability of Naïve Introspection,” Philosophical Review 117: 255273.

----- (2011) Perplexities of Consciousness. Cambridge, MA: MIT Press.

Smith, S., and Lane., R (2016) "Unconscious Emotion: A Cognitive Neuroscientific Perspective," Neuroscience and Biobehavioral Reviews 69: 216-38.

Tye, M. (2000). Consciousness, Color, and Content. Cambridge, MA: MIT Press.

---- M. (2008). "The Experience of Emotion: An Intentionalist Theory. Revue Internationale de Philosophie 243: 25-50.

Whiting, D. (2011) “The Feeling Theory of Emotion and the Object-Directed Emotions," European Journal of Philosophy 19: 281-301.

----- (2012) “Are Emotions Perceptual Experiences of Value?” Ratio 25 93-107.

---- (2016) “On the Appearance and Reality of Mind," Journal of Mind and Behavior 37: 47-70

----- (unpublished) “The Myth of Dispositional Emotions," Copy available on request.

Winkielman, P, Berridge, K, and Wilbarger, J. (2005) "Emotion, Behavior, and Conscious Experience: Once More without Feeling," in L. Barrett, P. Niedenthal, and P. Winkielman. (eds.) Emotion and Consciousness. London: Guildford Press.

Winkielman, P., Knutson, B., Paulus, M. and Trujillo, J. (2007) “Affective Influence on Decisions: Moving Towards the Core Mechanisms," Review of General Psychology. 11: 179-192.

Zajonc, R. (1980) "Feeling and Thinking: Preferences Need No Inferences," American Psychologist 35: $151-175$. 